\title{
Change of Obstruction Site by Modified Jaw Thrust Maneuver in Obstructive Sleep Apnea Patients
}

\author{
Soo-Kweon Koo, MD, PhD, Hyoung-Ju Lee, MD, Young-Joong Kim, MD, Young-Jun Kim, MD, Sung-Hoon Jung, MD \\ Department Otorhinolaryngology-Head and Neck Surgery, Busan Saint Mary's Hospital, Busan, Korea
}

Background and Objective We evaluated possibility of modified jaw thrust maneuver with drug induced sleep endoscopy (DISE), as an indicator of mandibular advancement treatment such as mandibular advance device, geniohyoid advancement and other treatment modalities.

Methods Sixty seven Korean male, obstructive sleep apnea patient, confirmed by full night polysomnography were enrolled. We performed DISE and analyzed obstruction sites before and after modified jaw thrust maneuver. Degree of improvement in obstruction more than one grade of obstruction, was defined as "responder by modified jaw thrust maneuver". Non-responder was defined as the airway does not open by the modified jaw thrust maneuver. Association was analyzed among the patient's characteristics [body mass in$\operatorname{dex}(\mathrm{BMI})$, Friedman stage, and respiratory disturbance index (RDI)] and the results.

Results In retropalatal level obstruction, responder by modified jaw thrust maneuver was most commonly observed at antero-posterior (AP) obstruction (70.31\%) while it was least observed at combined obstruction (66.67\%). In retroglossal level obstruction, responder by modified jaw thrust maneuver was most commonly observed at AP obstruction (77.50\%), while lateral obstruction was least observed (68.75\%). Between group comparisons including, group of responder and group of non-responder of combined obstruction of retropalatal level and lateral obstruction of retroglossal level, revealed that there were no statistically significant differences in BMI, Friedman stage, and RDI ( $\mathrm{p}<0.05)$.

Conclusions Airway obstruction did not extend to the same pattern by modified jaw thrust maneuver. Modified jaw thrust maneuver under DISE is a useful diagnostic tool and predictor of therapeutic effects of mandibular advancement treatment.

Sleep Med Res 2014;5(2):49-53

Key Words Sleep apnea, Obstructive, Diagnosis, Mandibular advancement.

Received: December 2, 2014

Revised: December 31, 2014

Accepted: December 31, 2014

Correspondence

Soo-Kweon Koo, MD, PhD

Department Otorhinolaryngology-Head and

Neck Surgery, Busan Saint Mary’s Hospital,

25-14 Yongho-ro 232beon-gil, Nam-gu,

Busan 608-838, Korea

Tel +82-51-933-7214

Fax +82-51-956-1956

E-mail koosookweon@naver.com

\section{INTRODUCTION}

Upper airway anatomical assessments such as CT, MRI, and cephalometric measurement are often static and performed during wakefulness, which may not represent dynamic upper airway behavior during sleep. Although drug induced sleep endoscopy (DISE) has some limitations, it approaches the natural physiologic state of sleep more than currently available diagnostic tools. It permits observation of the change of obstruction site, pattern by modified jaw thrust maneuver, lateral position, and other diagnostic manipulations. In patients with obstructive sleep apnea syndrome (OSAS) while sleeping, the lower jaw falls backward, allowing the base of tongue to lie against the posterior wall of the pharynx. ${ }^{1}$ Rearrangement of the anatomical position is possible through surgical procedures such as hyoid suspension, geniohyoid advancement, or nonsurgical methods such as mandibular advancement device (MAD). However not all patients are able to achieve a successful outcome on treatment with geniohyoid advancement, hyoid suspension, or MAD. Hence, the development of methods to aid in the selection of patients who would respond to treatment is of significant clinical importance. The purpose of this study was to address the following: The utility of modified jaw thrust maneuver to widen the airway space in all types of obstruction?; and the possibility that it can be an indicator of mandibular advancement treatment of OSAS patients? 


\section{METHODS}

\section{General Setting of Study}

The subjects included 67 Korean male. Inclusion criteria was the diagnosis of sleep apnea syndrome using all night polysomnography (WEE-1000 K, Nihon Kohden, Tokyo, Japan) in subjects who visited our hospital between December 2012 to January 2014. This study was performed with the approval of the Ethical Committee of Busan Saint Mary's Hospital, and the consent of all subjects. Before DISE, all patients received a thorough ear, nose, and throat examination, and a medical history was recorded. Patients with obvious retrognathia, mandibular dysplasia, or prior surgery of the soft palate or tongue, were excluded.

\section{Drug Induced Sleep Endoscopy}

The DISE technique was as follows. DISE was performed after application of local anesthetic spray in the nasal cavity. Sleep was induced by intravenous administration of midazolam $(0.07$ $\mathrm{mg} / \mathrm{kg}$ ) and patients were maintained in the supine position. In our study, DISE was performed with respiratory monitoring and with the help of an anesthesiologist in the operating room. Once asleep, a $4 \mathrm{~mm}$ flexible videolaryngoscope was introduced gently through the patient's nose. DISE was conducted by one otolaryngologist and the video images of recorded DISE were evaluated by three otolaryngologists, and obstruction type was classified according our classification system. ${ }^{2}$ We next performed modified jaw thrust maneuver and also evaluated the change of the obstruction type, after modified jaw thrust maneuver.

\section{Classification System}

We divided the pharynx into two portions: the retropalatal level (the region of posterior to the soft palate) and the retroglossal level (the region of the pharynx posterior to the vertical portion of the tongue). On this basis, we formulated our classification system. ${ }^{2}$ Our classification system included the site and degree of the obstruction: the retropalatal level was subdivided into the palate [antero-posterior (AP) diameter], lateral pharyngeal wall (lateral diameter), and combined (AP with lateral diameter). The retroglossal level was divided into the tongue base (AP diameter), the lateral pharyngeal wall (lateral diameter), and combined (AP with lateral diameter). Degree of airway obstruction was categorized as no obstruction (0), partial obstruction (1, 50-75\%), and complete obstruction $(2,>75 \%)$ : and improvement by more than one grade of obstruction, was defined as "responder by modified jaw thrust maneuver" (Table 1). Nonresponder was defined as the airway does not open by the modified jaw thrust maneuver.

Table 1. Classification of drug-induced sleep endoscopic finding

\begin{tabular}{|c|c|c|c|c|}
\hline \multirow[b]{2}{*}{ Obstruction level } & \multirow{2}{*}{$\begin{array}{c}\text { Degree of } \\
\text { obstruction* }\end{array}$} & \multicolumn{3}{|c|}{ Configuration } \\
\hline & & Antero-posterior diameter & Lateral diameter & $\begin{array}{c}\text { Combined: AP with lateral } \\
\text { diameter }\end{array}$ \\
\hline \multirow[t]{2}{*}{ Retropalatal } & $0 / 1 / 2$ & Palatal & LPW & Palate with LPW \\
\hline & & $0 / 1 / 2$ & $0 / 1 / 2$ & $0 / 1 / 2$ \\
\hline \multirow[t]{2}{*}{ Retroglossal } & $0 / 1 / 2$ & Tongue base & LPW & Tongue base with LPW \\
\hline & & $0 / 1 / 2$ & $0 / 1 / 2$ & $0 / 1 / 2$ \\
\hline
\end{tabular}

*Degree of obstruction has one number of each structure: $0=$ no obstruction (no vibration), $1=$ partial obstruction (vibration, $50-75 \%), 2=$ complete obstruction (collapse, $>75 \%$ ).

LPW: lateral pharyngeal wall, AP: antero-posterior.

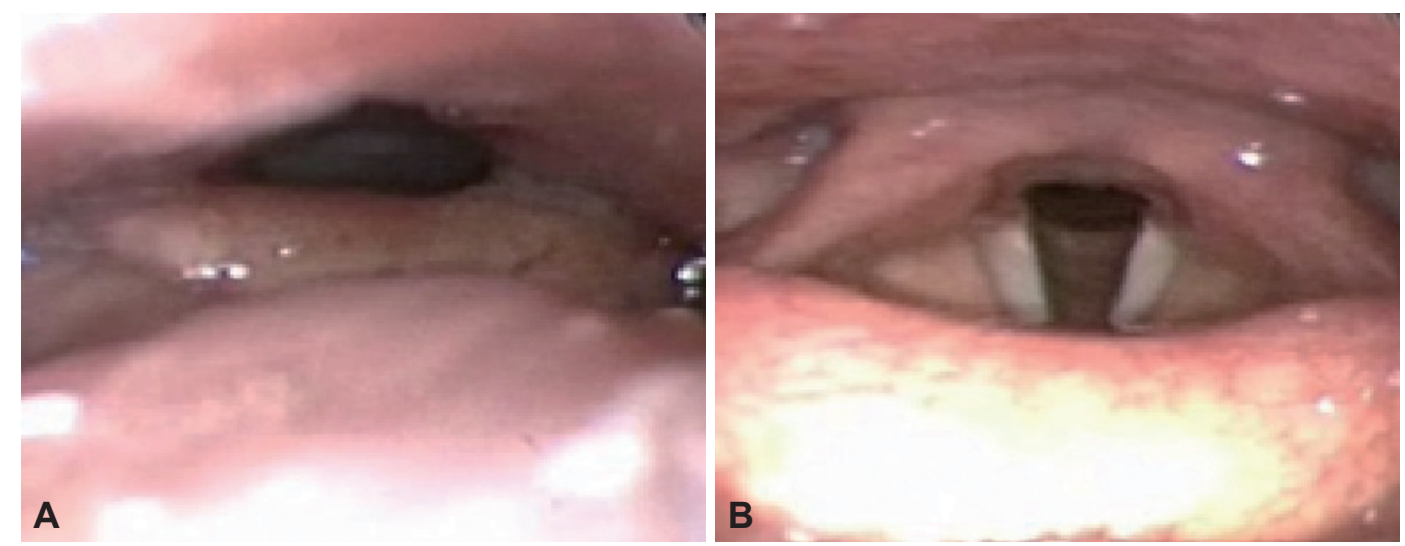

Fig. 1. The effect of modified jaw thrust maneuver. A: Pre-maneuver: it showed retroglossal level obstruction. B: Post-maneuver: widened airway by modified jaw thrust maneuver. 


\section{Relation between BMI, Friedman Stage, RDI and DISE Finding after Modified Jaw Thrust Maneuver}

Modified jaw thrust maneuver is done primarily by forward jaw thrust with minimum head extension. The sleep experiment was conducted while maintaining the patient in the nonwakeful state (Fig. 1). To determine the usefulness of other systemic parameters such as body mass index (BMI), Friedman stage, and respiratory disturbance index (RDI), we first selected the least responder group of each level; we then evaluated the difference between responder and non responder group according to the BMI, Friedman stage, and RDI.

\section{Statistical Analysis}

All statistical analyses were performed using Statistical Package for the Social Sciences (SPSS), version 18.0 (SPSS, Inc., an IBM Company, Chicago, IL, USA). The unpaired t test, MannWhitney test $U$ test was used to evaluate differences between the responder and non responder groups according to the BMI, Friedman stage, and RDI. Null hypotheses of no difference were rejected if p-values were less than 0.05. Results were presented as mean and standard deviation.

\section{RESULTS}

The study sample consisted of 67 male patients, their mean age was $39.85 \pm 13.29$ years, mean BMI $\left(\mathrm{kg} / \mathrm{m}^{2}\right)$ was $26.02 \pm$ 3.50 , mean Friedman stage was $2.60 \pm 0.78$, and mean RDI was $23.69 \pm 22.00$ (Table 2).

In retropalatal level obstruction, responders by modified jaw thrust maneuver were most commonly observed at AP obstruction $(70.31 \%)$, followed by lateral obstruction $(67.35 \%)$, and

Table 2. Patient characteristics (male, number of patients $=67$ )

\begin{tabular}{lc}
\hline Patient characteristics & Mean \pm SD \\
\hline Age & $39.85 \pm 13.29$ \\
BMI, $\mathrm{kg} / \mathrm{m}^{2}$ & $26.02 \pm 3.50$ \\
Friedman stage & $2.60 \pm 0.78$ \\
RDI & $23.69 \pm 22.00$ \\
\hline
\end{tabular}

SD: standard deviation, BMI: body mass index, RDI: respiratory disturbance index. combined obstruction was least observed (66.67\%). In retroglossal level obstruction, responders by modified jaw thrust maneuver were most commonly observed at AP obstruction (77.50\%), followed by combined obstruction (72.41\%) and lateral obstruction (68.75\%). Hence, the least responder group was combined obstruction (66.67\%) of retropalatal level and lateral obstruction (68.75\%) in retroglossal level (Table 3).

In retropalatal level, comparison between group of responders (32 patients) and group of non-responders (16 patients) in combined obstruction (least responder group), there were no statistically significant differences in BMI $(\mathrm{p}=0.182)$, Friedman stage $(p=0.961)$, and RDI $(p=0.297)$ (Table 4$)$.

In retroglossal level, comparison between group of responders (33 patients) and group of non-responders (15 patients) in lateral obstruction (least responder group), there were likewise no statistically significant differences in BMI $(p=0.059)$, Friedman stage $(\mathrm{p}=0.238)$, and RDI $(\mathrm{p}=0.344)$ (Table 5).

\section{DISCUSSION}

Loss of consciousness during emergent condition is often accompanied by airway obstruction by posterior displacement of

Table 3. The percent of responder by modified jaw thrust maneuver according to obstruction site

\begin{tabular}{lccc}
\hline $\begin{array}{c}\text { Obstructive } \\
\text { pattern }\end{array}$ & $\begin{array}{c}\text { No. of } \\
\text { patients }\end{array}$ & Responder & $\begin{array}{c}\text { Percent } \\
(\%)\end{array}$ \\
\hline $\begin{array}{l}\text { Retropalatal level } \\
\text { AP obstruction }\end{array}$ & 64 & 45 & 70.31 \\
Lat obstruction & 49 & 33 & 67.35 \\
Combined obstruction & 48 & 32 & 66.67 \\
Retroglossal level & & & \\
AP obstruction & 40 & 31 & 77.50 \\
Lat obstruction & 48 & 33 & 68.75 \\
Combined obstruction & 29 & 21 & 72.41 \\
\hline
\end{tabular}

Each level and structure is considered separately, with percentages expressed as a fraction of total number of each subgroup. Percentages sum to greater than $100 \%$ because it was possible for a patient to have more than one structure contributing to airway obstruction. No.: number, AP: antero-posterior, Lat: lateral.

Table 4. Comparison of patients between responder and non-responder of combined obstruction in retropalatal level

\begin{tabular}{lccc}
\hline & Responder $($ mean $\pm \mathrm{SD})$ & Non-responder $($ mean \pm SD) & $\mathrm{p}$-value \\
\hline No. of patients & 32 & 16 & 0.358 \\
Age & $38.41 \pm 12.28$ & $42.81 \pm 13.54$ & 0.182 \\
BMI, kg/m $\mathrm{m}^{2}$ & $26.26 \pm 3.82$ & $27.62 \pm 3.42$ & 0.961 \\
Friedman stage & $2.69 \pm 0.69$ & $2.69 \pm 0.79$ & 0.279 \\
RDI & $21.11 \pm 21.66$ & $29.15 \pm 27.15$ & \\
\hline
\end{tabular}

p-value $<0.05$ is significant value.

SD: standard deviation, BMI: body mass index, RDI: respiratory disturbance index, No.: number. 
Table 5. Comparison of patients between responder and non-responder of lateral obstruction in retroglossal level

\begin{tabular}{lccc}
\hline & Responder $($ mean \pm SD) & Non-responder $($ mean \pm SD) & p-value \\
\hline No. of patients & 33 & 15 & 0.672 \\
Age & $38.61 \pm 13.15$ & $41.47 \pm 12.54$ & 0.059 \\
BMI, $\mathrm{kg} / \mathrm{m}^{2}$ & $25.24 \pm 2.80$ & $27.48 \pm 4.43$ & 0.238 \\
Friedman stage & $2.52 \pm 0.80$ & $2.80 \pm 0.76$ & 0.344 \\
RDI & $18.75 \pm 13.79$ & $24.88 \pm 21.35$ & \\
\hline
\end{tabular}

p value $<0.05$ is significant value.

SD: standard deviation, BMI: body mass index, RDI: respiratory disturbance index, No.: number.

the tongue or epiglottis. It is already known that the 'jaw thrust maneuver' is an effective maneuver in clearing the airway. ${ }^{3}$ When neck extension is unsafe or impossible as with extant or potential cervical spine injuries, rheumatoid or degenerative disease, or ankylosing spondylitis, the jaw thrust maneuver alone may be used without hyperextending the neck (modified jaw thrust maneuver) to improve nasal airway patency. ${ }^{3}$ Modified jaw thrust maneuver conducted under the DISE, allowed us to indirectly asses the degree of extension of the airway, in patients with sleep apnea. Mandibular advancement treatment such as $\mathrm{MAD}$, and geniohyoid advancement are now indicated for various degrees of obstructive sleep apnea. ${ }^{4-6}$ However, one issue in the clinical setting, is that different studies have used different criteria for measuring success in response to mandibular advancement treatment have used.,

The principle of mandibular advancement treatment is the restoration of airway from obstruction and reduction in collapsibility. ${ }^{7}$ In several studies, airway obstruction was not caused by simply a pushed back tongue, but rather a combined obstruction of several parts of the airway. ${ }^{8,9}$ Thus, there is a need for a more dynamic diagnostic study for evaluating the effect of mandibular advancement treatment. ${ }^{10}$

In our study, modified jaw thrust maneuver did not result in a favorable response in the combined type obstruction group of retropalatal level, and lateral obstruction group of retroglossal level, we therefore emphasized the importance of lateral part of obstruction. But the response of AP obstruction was generally good. These studies reveal the critical importance of near lateral closure in determining the success of mandibular advancement treatment. From this perspective, the lateral portion of the airway that can be closed on CT or MRI, ${ }^{11}$ however the disadvantage of these diagnostic methods, is the cost and exposure to radiation. On the other hand, DISE has the advantage of being patient friendly. The evolution of sleep endoscopic technique has led to the formulation of various grading systems. Ideally, the system should cover the entire upper airway, be both simple and practical, and provide a means to quantify the severity of the obstruction. These criteria were taken into consideration when we introduced our classification. ${ }^{2,12}$ Fujita et al. ${ }^{13}$ divided the upper airway functionally into two portions: the retropalatal pharynx (the region of the pharynx posterior to the soft palate) and the retroglossal pharynx (the region of the pharynx posterior to the vertical portion of the tongue). The division of the pharynx into these sections does not represent a formal anatomic classification but, rather, a descriptive paradigm that appears to have relevance to functional and surgical considerations.

In the comparative study of the least responder groups in each level, systemic parameter such as BMI, Friedman stage, and RDI did not have statistical significance. This result suggested that the modified jaw thrust maneuver performed under DISE was superior in diagnostic value and predicting therapeutic efficacy. In fact, several other studies have reported similar results. ${ }^{10,14-20}$ Our data showed that, the evaluation of morphological changes in the airway was important, to determine whether mandibular advancement treatment was indicated. In recent years, there have been a few reports on MAD in the dental field. Such studies were designed to directly measure the effects of mandibular advancement treatment, with the added advantage of directly predicting the treatment effect. The current research study was slightly limited in this regard. However, as in the otolaryngologic field, the respiratory tract simply cannot be classified as oropharynx and hypopharynx alone. There are many different surgical approaches besides MAD, hence research similar to our study will likely need to focus on a surgical treatment based classification scheme, in the ENT field. Our research was conducted on Asian males who tend to be westernized in lifestyle, but with distinct racial aspects to the anatomy, a point that may also need to be emphasized.

In summary, modified jaw thrust maneuver for all types of airway obstruction is implicitly understood not to result in enforcement of extension to the same pattern, in all cases. Modified jaw thrust maneuver under DISE is a useful diagnostic tool and predictor of therapeutic effects of mandibular advancement treatment.

\section{Conflicts of Interest}

The authors have no financial conflicts of interest.

\section{REFERENCES}

1. Guedel AE. Inhalation anesthesia: a fundamental guide. New York: The Macmillan Company 1937;15-106.

2. Koo SK, Choi JW, Myung NS, Lee HJ, Kim YJ, Kim YJ. Analysis of obstruction site in obstructive sleep apnea syndrome patients by drug induced sleep endoscopy. Am J Otolaryngol 2013;34:626-30. 
3. Uzun L, Ugur MB, Altunkaya H, Ozer Y, Ozkocak I, Demirel CB. Effectiveness of the jaw-thrust maneuver in opening the airway: a flexible fiberoptic endoscopic study. ORL J Otorhinolaryngol Relat Spec 2005; 67:39-44.

4. Kushida CA, Morgenthaler TI, Littner MR, Alessi CA, Bailey D, Coleman J Jr, et al. Practice parameters for the treatment of snoring and Obstructive Sleep Apnea with oral appliances: an update for 2005. Sleep 2006;29:240-3

5. Ferguson KA, Cartwright R, Rogers R, Schmidt-Nowara W. Oral appliances for snoring and obstructive sleep apnea: a review. Sleep 2006; 29:244-62.

6. Marklund M, Verbraecken J, Randerath W. Non-CPAP therapies in obstructive sleep apnoea: mandibular advancement device therapy. Eur Respir J 2012;39:1241-7.

7. Ng AT, Gotsopoulos H, Qian J, Cistulli PA. Effect of oral appliance therapy on upper airway collapsibility in obstructive sleep apnea. Am J Respir Crit Care Med 2003;168:238-41.

8. Lowe AA. Can we predict the success of dental appliance therapy for the treatment of obstructive sleep apnea based on anatomic considerations? Sleep 1993;16(8 Suppl):S93-5.

9. Henke KG, Frantz DE, Kuna ST. An oral elastic mandibular advancement device for obstructive sleep apnea. Am J Respir Crit Care Med 2000; 161(2 Pt 1):420-5.

10. Liu Y, Lowe AA, Fleetham JA, Park YC. Cephalometric and physiologic predictors of the efficacy of an adjustable oral appliance for treating obstructive sleep apnea. Am J Orthod Dentofacial Orthop 2001;120:639-47.

11. Mayer G, Meier-Ewert K. Cephalometric predictors for orthopaedic mandibular advancement in obstructive sleep apnoea. Eur J Orthod
1995; 17:35-43.

12. Kezirian EJ, Hohenhorst W, de Vries N. Drug-induced sleep endoscopy: the VOTE classification. Eur Arch Otorhinolaryngol 2011;268:1233-6.

13. Fujita S, Conway W, Zorick F, Roth T. Surgical correction of anatomic azbnormalities in obstructive sleep apnea syndrome: uvulopalatopharyngoplasty. Otolaryngol Head Neck Surg 1981;89:923-34.

14. Otsuka R, Almeida FR, Lowe AA, Ryan F. A comparison of responders and nonresponders to oral appliance therapy for the treatment of obstructive sleep apnea. Am J Orthod Dentofacial Orthop 2006;129:222-9.

15. Horiuchi A, Suzuki M, Ookubo M, Ikeda K, Mitani H, Sugawara J. Measurement techniques predicting the effectiveness of an oral appliance for obstructive sleep apnea hypopnea syndrome. Angle Orthod 2005; 75:1003-11.

16. Hoekema A, Doff MH, de Bont LG, van der Hoeven JH, Wijkstra PJ, Pasma HR, et al. Predictors of obstructive sleep apnea-hypopnea treatment outcome. J Dent Res 2007;86:1181-6.

17. Tsuiki S, Lowe AA, Almeida FR, Fleetham JA. Effects of an anteriorly titrated mandibular position on awake airway and obstructive sleep apnea severity. Am J Orthod Dentofacial Orthop 2004;125:548-55.

18. Zeng B, Ng AT, Darendeliler MA, Petocz P, Cistulli PA. Use of flow-volume curves to predict oral appliance treatment outcome in obstructive sleep apnea. Am J Respir Crit Care Med 2007;175:726-30.

19. Mehta A, Qian J, Petocz P, Darendeliler MA, Cistulli PA. A randomized, controlled study of a mandibular advancement splint for obstructive sleep apnea. Am J Respir Crit Care Med 2001;163:1457-61.

20. Marklund M, Stenlund H, Franklin KA. Mandibular advancement devices in 630 men and women with obstructive sleep apnea and snoring: tolerability and predictors of treatment success. Chest 2004;125:1270-8. 